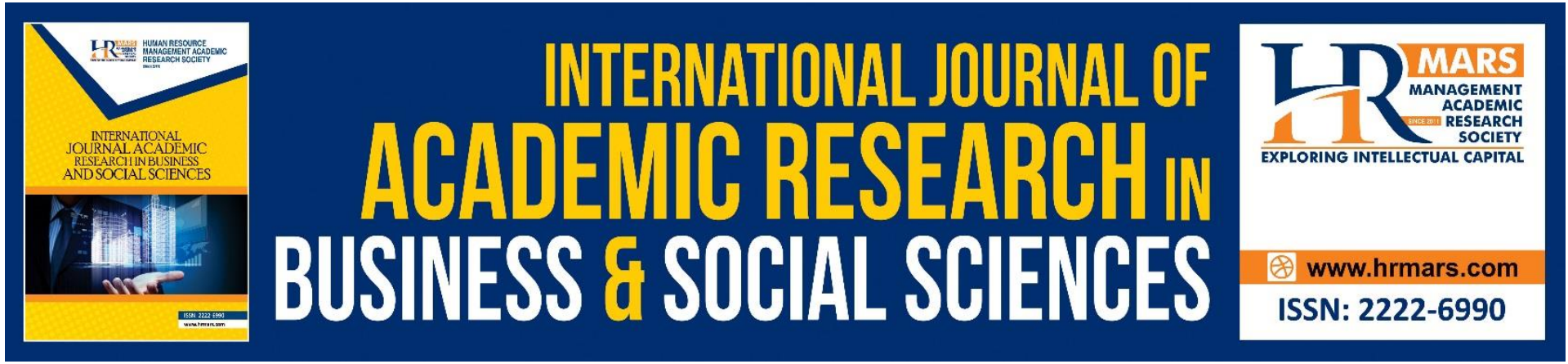

\title{
The Relationship between Achievement Goal Orientations and Language Performance of Secondary School EFL Learners in China
}

Wang Ruishi, Gurnam Kaur Sidhu and Priyadarshini Muthukrishnan

To Link this Article: http://dx.doi.org/10.6007/IJARBSS/v11-i7/10425

DOI:10.6007/IJARBSS/v11-i7/10425

Received: 16 May 2021, Revised: 19 June 2021, Accepted: 30 June 2021

Published Online: 07 July 2021

In-Text Citation: (Ruishi et al., 2021)

To Cite this Article: Ruishi, W., Sidhu, G. K., \& Muthukrishnan, P. (2021). The Relationship between Achievement Goal Orientations and Language Performance of Secondary School EFL Learners in China. International Journal of Academic Research in Business and Social Sciences, 11(7), 139-149.

Copyright: @ 2021 The Author(s)

Published by Human Resource Management Academic Research Society (www.hrmars.com) This article is published under the Creative Commons Attribution (CC BY 4.0) license. Anyone may reproduce, distribute, translate and create derivative works of this article (for both commercial and non-commercial purposes), subject to full attribution to the original publication and authors. The full terms of this license may be seen at: http://creativecommons.org/licences/by/4.0/legalcode

Vol. 11, No. 7, 2021, Pg. 139 - 149

Full Terms \& Conditions of access and use can be found at http://hrmars.com/index.php/pages/detail/publication-ethics 


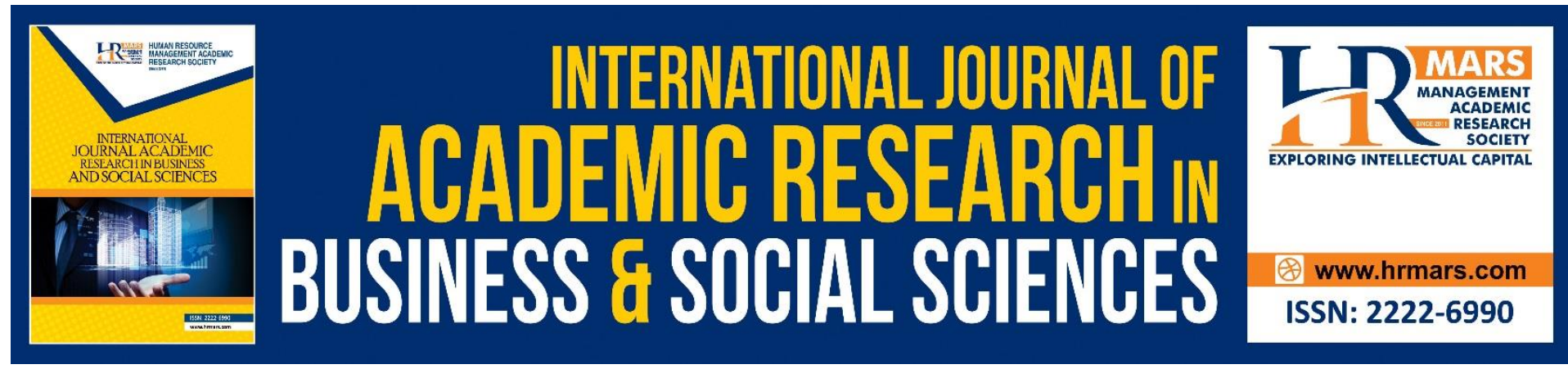

\title{
The Relationship between Achievement Goal Orientations and Language Performance of Secondary School EFL Learners in China
}

\author{
Wang Ruishi ${ }^{1}$, Gurnam Kaur Sidhu ${ }^{2}$ and Priyadarshini \\ Muthukrishnan ${ }^{3}$ \\ ${ }^{1 \& 2}$ SEGi University, Petaling Jaya, Malaysia, ${ }^{3}$ HELP University, Selangor, Malaysia \\ Email: wangruishi0912@gmail.com /gurnamgurdial@segi.edu.my
}

\begin{abstract}
Research in second and foreign language teaching and learning has indicated that there are many factors that influence language performance. These factors can be broadly divided into internal and external factors. This study investigated the impact of one internal factor, namely achievement goal orientations. It explored four types of achievement goal orientations namely mastery approach orientation, mastery avoidance orientation, performance approach orientation and performance avoidance orientation. This non-experimental quantitative study involved 360 Grade Eight Secondary school students from five randomly selected schools located in the Tongcheng County in Hubei Province, China. Data were collected using a survey questionnaire and the findings were analyzed using SPPS version 27. The findings indicated that there was a significant and positive relationship between achievement goal orientations and language performance. Mastery approach orientation, and mastery avoidance orientation however showed a significant, moderate and positive relationship, performance approach orientation showed a significant, low and positive relationship and performance avoidance orientation showed a very low and negative relationship with language performance. Overall, these findings imply that achievement goal orientations should be further explored as potential factors influencing language performance in English as a Foreign Language (EFL) classrooms.
\end{abstract}

Keywords: Achievement Goal Orientation, EFL Learners, Language Performance

\section{Introduction}

With the development of interconnectivity and globalization all over the world, the importance of immediate and appropriate ways of communication has been increasing very rapidly in this modern world. This has also witnessed the use and status of English currently reaching an unprecedented height even though basic culture and political tensions remain. Mackey (2003), notes that it is rather difficult to confirm the number of people who are learning English as a foreign language (EFL, hereafter) in China because how a "user" is defined and the methods deployed for counting. Zhao and Campbell (1995) suggest a figure of 200-300 million users of English, based on the number of schools and college graduates because all students study English at some point in their education. (In the past decades the 
population growth would inflate that figure by some 50 million, resulting in a total that equates to the entire population of America.) Obviously, not all of these people can speak fluent English even at all. Some researchers suggest that some students who have graduated for several years have very little or even no command of English. But this figure shows the significance of the language in the Chinese society, and depending on one's viewpoint, the size of the potential damage that could accurate to the cultural integrity of that society or of the potential contribution that English could contribute to the economic development of China.

In recent years, the teaching and learning of EFL has achieved great success. Nonetheless, Shuang Shan (2018) highlights that though the EFL has witnessed improvement in urban areas, English language acquisition in rural areas leaves much to be desired. This is notable in rural secondary schools as interest and exposure to English is limited as Chinese EFL students live and function in a homogeneous environment where Mandarin is the main medium of instruction and also the official language of communication in the country. Besides the gap of difference in EFL between urban and rural secondary schools students another challenge lies in students possessing varying language proficiency level in EFL in one intact EFL classroom. All these are challenges in the teaching and learning of English in Chinese EFL classrooms.

Researchers such as Richards and Rodgers (2014) note that there are numerous factors that influence language learning. These factors can be divided into two main categories such as internal and external factors. External factors include teacher instruction, curriculum, culture, status of the language, access to native speaker and extrinsic motivation. On the other hand, internal factors include a variety of factors such as intrinsic motivation, aptitude, personality traits, interest, attitude and aptitude. Another internal factor that has recently gained attention with regards to language performance is achievement goal orientation (Anderman, Youth \& Gimbert, 2010).

Achievement orientation is said to have an effect on a student's performance. It refers to how a student reacts and interprets a learning task which results in various aspects of cognition and behaviour. Alongside this are achievement goals which take into consideration the aim and focus of a student's achievement behaviour. Academic achievement is often regarded as one of the most important educational outcomes. Researcher and participants are interested in the relations between goal orientations and achievement since academic achievement is greatly regarded as an indicator of educational performance). Therefore, this study aimed to investigate EFL secondary school students' achievement goal orientations with regards to language performance. The study was guided by the following three main research questions:

- What is the level of achievement goal orientations among secondary school EFL learners in China?

- What is the relationship between achievement goal orientations and English language performance?

- Which of the predictor variables (mastery approach, mastery avoidance, performance approach, and performance avoidance) make a statistically significant contribution to variance in student language achievement? 


\section{Literature Review}

The following literature review outlines the main theories, concepts and findings related to the main research questions in the study.

\section{Achievement Goal Theory}

Dweck (1986) developed goal theory, which focuses on ones' goal orientations toward achievement in academic tasks. He reiterated that besides ability there are numerous factors that affect learning and these factors can be viewed in the light as to whether students seek or avoid challenges and whether they persist or withdraw in the face of challenges and to what extent they employ and develop their skills effectively. He also pointed out that under Goal theory, a student's individual behaviour can be rational or economic in a bid to achieve certain goals and hence Goal Theory can to a certain extent make predictions about a student's learning behaviour and its learning outcomes (Miyamoto \& Nasu, 1995).

\section{Current Four-Factors Model of Achievement Theory}

Achievement goal orientation has four aspects. Mastery approach orientation: trying to attain competence relative to the task or personal standards (students are motivated to learn or develop skills); Mastery avoidance orientation: trying to avoid incompetence relative to the task or personal standards (students are motivated to avoid failures or become de-skilled). Performance approach orientation: trying to attain competence relative to one's peers (students are motivated to outdo others or to be considered talented). Performance avoidance orientation: trying to avoid incompetence relative to one's peers (students are motivated to avoid doing worse than others or to be considered less talented) (Elliot and McGregor, 2001).

Many researchers studied the distinction of mastery or performance. For many years (Anderman \& Wolters, 2006; Urdan, 1997) However, in the mid-1990s, several researchers thought that the distinction between approach and avoid orientation should be considered within a good orientation framework. Elliot and Harackiewickz (1996) noted that some early work by achievement goal researchers such as Dweck and Nicholls did distinguish of performance goals, but these distinctions were lost in late definitions.

A trichotomous framework for achievement goals suggests that in addition to mastery goals, a distinction should be made between performance-approach and performance-avoid goals (Elliot, 1999). Elliot and Harackiewicz (1996) initially conducted experiments in which participants were asked to use mastery goals, performance-approach goals and performanceavoid goals. Participants in the performance-approach condition were informed that these student who has good competence to solve problems better than other student who were at the same university. (P. 468); In contrast, students in the performance-avoid condition were told that if they solved fewer puzzles than others, they would demonstrate that they "have poor puzzle solving ability" (p. 468). Results indicated that participants in the performanceavoid condition displayed lower intrinsic motivation to the puzzles than those in the performance-approach condition.

Midgley and her collegues developed a widely used criterion of achievement goals, the patterns of Adaptive Learning Survey (PALS) (Midgley at al., 2000). At the beginning, they made different performance-approach and performance-avoid goal orientations (Middleton \& Midgley, 1997). By a large sample of middle school students, Middleton and Midgley demonstrated that performance-approach goals can be divided into performance-approach and performance-avoid goal orientations, They operationalized performance-approach goals 
in terms of students (a) writing to do better than other students in their class and (b) wanting to demonstrate that they are more competent than others; in contrast, performance-avoid goals were operationalized in terms of wanting to avoid appearing incompetent or "dumb". Skaalvik (1997) also studies different kinds of performance goals. Specially, using a sample of Norwegian sixth and eighth grade students, Skaalvik developed a measure of self-defeating ego orientation (similar to a performance-avoid goal orientation).

The approach/avoid distinction was also applied to mastery goal orientation, resulting in a 2 $\times 2$ framework for achievement goals (Elliot \& McGregor, 2001). In this model, mastery goals are divided into mastery-approach and mastery-avoid goals, matching the separation of performance-approach and performance-avoid goals. The new addition to the model was the mastery-avoid construct. A student who supported mastery-avoid goals wants to avoid misunderstanding or losing a sense of competence. The $2 \times 2$ model has been supported in both North American (Conroy, Eliiot \& Hofer, 2003) and international samples (Bong, 2009). So far, goal orientation theorists generally supported the $2 \times 2$ model. While, the validity of mastery-avoid goals has been questioned (e.g., Sideridis \& Mouratidis, 2008). Specially, some researchers questioned whether individuals actually think about mastery-avoid goals in real life situations. Ciani and Sheldon (2010) conducted a qualitative study in which they had an interview to my college baseball players about their endorsement of mastery-avoid goals while playing baseball. Although players endorsed both high and low levels of mastery-avoid goals, when players who endorsed mastery- avoid goals were probed about their beliefs, Ciani and Sheldon suggested that for this may be that is difficult to ley learners know distinction about "mastery-avoid" goals and use survey instrument.

In addition, some research (Urdan \& Mestas, 2006) suggests some students have difficult in distinguishing performance-approach and performance-avoid goals. For example, Urdan and Mestas (2006) conducted an interview with 53 high school seniors who all reported high levels of performance-avoid goals (as determined by responses to a survey). Students were probed about responses to various survey items. Results indicated that they pursue performance goals for a variety of reasons. (e.g., to look smart, to please parents, to look smart, to please parents, to look smart to one's peers, or simply because students enjoyed competition). Additional work on the measurement, interpretation, and predictive validity of mastery-avoid goal orientation will be an important area for future research. In the past two decades, much of the research conducted by achievement goal theories has focused on relations between students' goal orientations and a variety of academic outcome, including implicit beliefs of grit, academic achievement and growth mindset.

\section{Goal Orientations and Academic Achievement}

Academic achievement is often regarded as one of the most important educational outcomes. Researcher and participants are interested in the relations between goal orientations and achievement since academic achievement is greatly regarded as an indicator of educational performance ( Anderman, Youth \& Gimbert, 2010).

Relations between goal orientations and academic achievement are somewhat inconsistent. Although the reasons are not clear, much depends on how student achievement is measured by different kinds of ways. (e.g., scores on standard tests, teacher made tests, or teacherassigned grades that may or may not include homework or conduct) and do not reflect students' real understanding. A mastery goal orientation, with its accompanying thoughtfulness and strategic effort, is only likely to be important if achievement tests require 
students to demonstrate deep understanding. In addition, a very strong desire to outscore others may lead students to having inflated achievement scores by means such as cheating.

\section{Methods}

This study aimed to explore the relationship between achievement goal orientations and English language performance. In this study, the independent variables are achievement goal orientations (i.e. mastery approach, mastery avoidance, performance approach, and performance avoidance) whilst the dependent variable is language performance. The study used a non-experimental survey design to collect data and to examine the multiple of interrelationships among the variables of the study. According to Creswell (2018), when researchers try to understand the relationships between variables, a quantitative approach is appropriate.

The study was conducted in the Tongcheng County, located in Hubei province in China. The study involved Grade $8 \mathrm{EFL}$ students from five (5) randomly selected secondary schools. The final population sample comprised a total of $360 \mathrm{EFL}$ students and data were collected via a questionnaire, namely the Students' Motivation in Learning English Questionnaire (SMLEQ). The questionnaire was validated by a panel of two experts and the reliability was established through a pilot test (Cronbach Alpha= 0.754).

\section{Results}

The following section will present the findings based on the three research questions that guided this study. The first research question in this study explored the level of achievement goal orientations among secondary school EFL learners in China. The items of this section were divided into four aspects, namely mastery approach orientation, mastery avoidance orientation, performance approach orientation and performance avoidance orientation. For these four aspects, students were required to respond to the items based on a 5-point Likert scale. In this study, a score of 4 and above would indicate a positive agreement to the items. This would reveal the respondent possess a high level of orientation toward the items. While a score of 3 and above would demonstrate a moderate level of agreement while a score of below 3 would exhibit a low level of agreement. The overall findings are presented in Table 1 below.

Table 1

Achievement Goal Orientations among Secondary School EFL Learners in China

\begin{tabular}{lll}
\hline No. Item & Mean & SD \\
\hline 1. Overall of mastery approach orientation & 3.82 & 0.949 \\
2. Overall of mastery avoidance orientation & 3.46 & 0.982 \\
3. Overall of performance approach orientation & 3.42 & 1.086 \\
4. Overall of performance avoidance orientation & 3.31 & 1.085 \\
\hline \multicolumn{1}{l}{ Overall } & $\mathbf{3 . 5 0}$ & $\mathbf{1 . 0 2 6}$ \\
\hline
\end{tabular}

Scale: 1= Strongly Disagree, 2= Disagree, 3= Somewhat Agree, 4= Agree, 5= Strongly Agree

From the findings above it can be seen, that students possess a moderate perception towards achievement goal orientations $(M=3.50, S D=1.026)$. They also displayed a positive perception toward mastery approach ( $\mathrm{M}=3.82, \mathrm{SD}=0.949)$. 
The second research question investigated the relationship between achievement goal orientations and English language performance. The achievement goal orientations were investigated based on four aspects, namely mastery approach orientation, mastery avoidance orientation, performance approach orientation and performance avoidance orientation. The results displayed in Table 2 below reveal that there was a significant and positive relationship between achievement goal orientations and language performance. Mastery approach orientation, and mastery avoidance orientation showed a significant, moderate and positive relationship $\left(r=.418^{* *} ; p<.001\right.$ and $\left.r=.438^{* *} ; p<.001\right)$, performance approach orientation showed a significant, low and positive relationship $\left(r=.281^{* *} ; p<.001\right)$ and performance avoidance orientation showed a very low and negative relationship ( $r=-.019 ; p>0.05)$ with language performance. The relationships among mastery approach orientation, mastery avoidance orientation, performance approach orientation, performance avoidance orientation were significant and positive.

Table 2

Relationship between Achievement Goal Orientations and Language Performance in English $(n=360)$

\begin{tabular}{|c|c|c|c|c|c|c|}
\hline Variables & $\begin{array}{l}\text { Mean } \\
\text { (SD) }\end{array}$ & MAp & MAv & PAp & PAv & ELP \\
\hline $\begin{array}{l}\text { Mastery Approach } \\
\text { (MAp) }\end{array}$ & $\begin{array}{l}3.82 \\
(0.949)\end{array}$ & 1 & & & & \\
\hline $\begin{array}{l}\text { Mastery Avoidance } \\
\text { (MAv) }\end{array}$ & $\begin{array}{l}3.46 \\
(0.982)\end{array}$ & $\begin{array}{l}.681^{* *} \\
.000\end{array}$ & 1 & & & \\
\hline Performance & 3.42 & $.445^{* *}$ & $.504^{* *}$ & 1 & & \\
\hline Approach & (1.086) & .000 & .000 & & & \\
\hline (PAp) & 3.31 & $.186 * *$ & $.305^{* *}$ & $.470 * *$ & 1 & \\
\hline $\begin{array}{l}\text { Performance } \\
\text { Avoidance }\end{array}$ & $(1.085)$ & .000 & .000 & .000 & & \\
\hline (PAv) & 2.03 & $.418^{* *}$ & $.438 * *$ & $.281 * *$ & -.019 & 1 \\
\hline $\begin{array}{l}\text { English } \\
\text { Language } \\
\text { Perfomance } \\
\text { (ELP) }\end{array}$ & $(0.826)$ & .000 & .000 & .000 & .716 & \\
\hline $\begin{array}{l}\text { (MAp=Mastery Ap } \\
\text { PAp=Performance Af } \\
\text { English Language Per } \\
*^{*} \text { Correlation is signi } \\
*^{*} p<0.01,{ }^{*} p<0.05\end{array}$ & $\begin{array}{l}\text { ch OI } \\
\text { ich Orie } \\
\text { ance) } \\
t \text { at the }\end{array}$ & $\begin{array}{l}\text { ntation; } \\
\text { ation; } \\
1 \text { level }\end{array}$ & $\begin{array}{r}\quad M A v= \\
v=\text { Perfo } \\
\text {-tailed). }\end{array}$ & $\begin{array}{l}\text { astery } \\
\text { ance } A\end{array}$ & $\begin{array}{l}\text { Avoi } \\
\text { oidan }\end{array}$ & $\begin{array}{l}\text { ce } \\
\text { Orie }\end{array}$ \\
\hline
\end{tabular}

The third research question examined which of the predictor variables (mastery approach, mastery avoidance, performance approach, and performance avoidance) make a statistically significant contribution to variance in student language achievement. Here the data were analysed employing step-wise multiple regression which is a statistical measure that employs step-by-step iterative construction of a regression model involving several explanatory variables (e.g. mastery approach, mastery avoidance, performance approach and performance avoidance) to predict the outcome (language performance) by adding or 
removing potential explanatory variables in succession testing for statistical significance after each iteration. The results are shown in Table 3 below.

In the first stage of the stepwise multiple regression, when mastery approach orientation of the students was entered into the model, the results showed that there was a significance with a variance of $17.5 \%$ in predicting the English language performance of the EFL learners $\left(R^{2}=.175\right.$, adjusted $\left.R^{2}=.172\right)$. The $F$ statistic $(F(1,358)=75.713 ; p<0.05)$ confirmed the model 1 was significant.

In the second stage of the model, when mastery avoidance orientation was entered into the model, it could explain $21.8 \%$ of the variance in predicting English language performance. The $F$ statistic confirmed model 2 with the $F$ statistic value $(F(2,357)=49.864 ; p<0.001)$ was significant and the change in $R^{2}$ value was low $\left(R^{2}\right.$ change $\left.=.043\right)$.

In the third stage of the step-wise regression analysis, performance approach orientation was entered with other variables which were entered in the step 1 and 2 . The results confirmed that performance approach orientation is a significant predictor for the English language performance. The model 3 can explain $22.0 \%$ of variance in independent variable, the change of $R^{2}$ was very low $\left(R^{2}=.002\right)$. $F$ statistic confirmed that model was significant $(F(3,356)=$ 33.539; $p<0.05)$.

Table 3

Step-wise multiple regression analysis: Achievement Goal Orientations

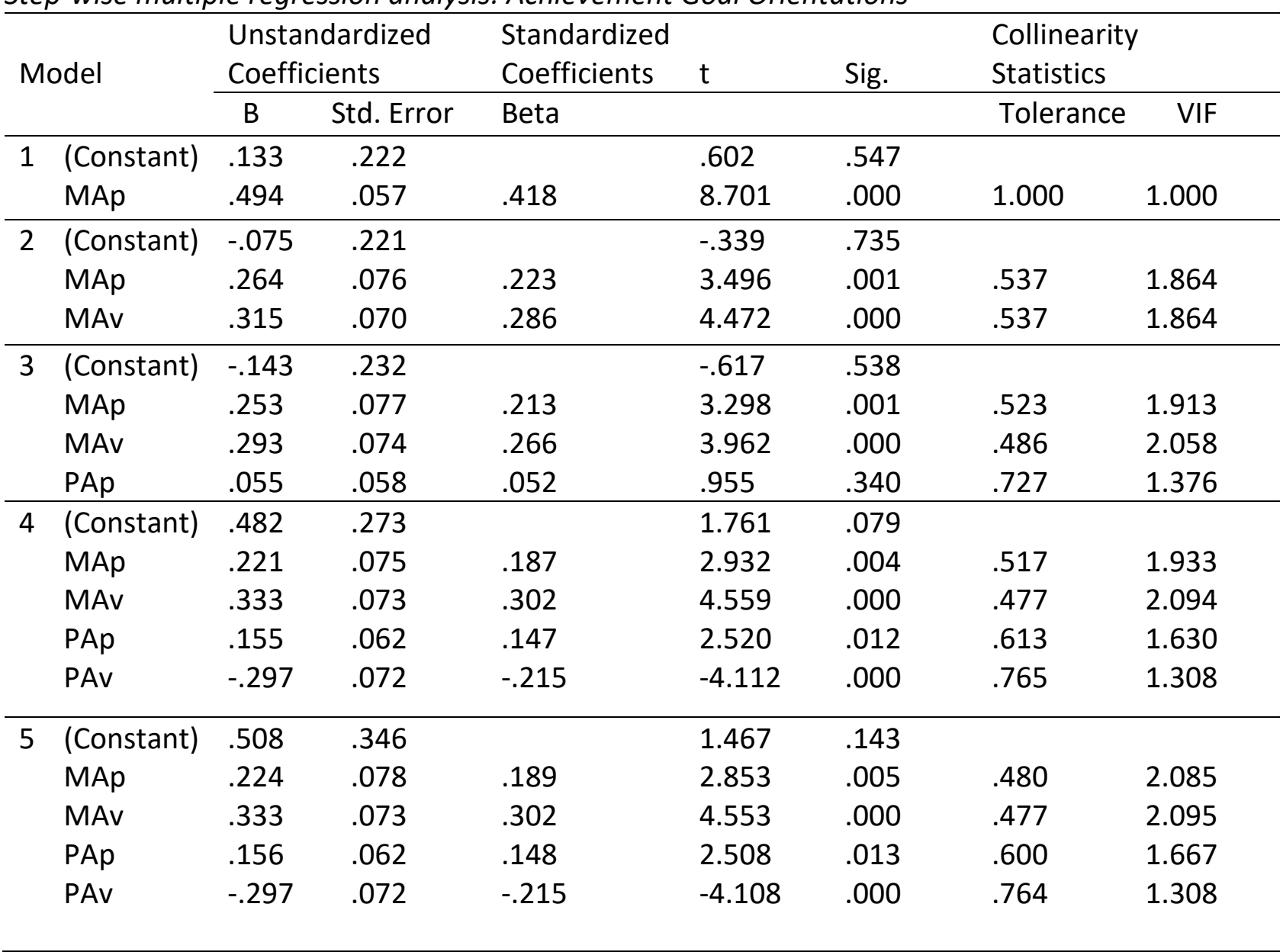

** $\mathrm{p}<0.01$, Dependent Variable: Academic achievement

1. Predictors: (Constant), Mastery Approach Orientation 
2. Predictors: (Constant), Mastery Approach Orientation, Mastery Avoidance Orientation

3. Predictors: (Constant), Mastery Approach Orientation, Mastery Avoidance Orientation, Performance Approach Avoidance

4. Predictors: (Constant), Mastery Approach Orientation, Mastery Avoidance Orientation, Performance Approach Avoidance, Performance Avoidance

In the fourth stage of regression analysis, performance avoidance was entered in the model 4. The results showed that performance avoidance orientation is a significant predictor for the English language performance and this model was significant $(F(4,355)=30.505 ; p<0.001$. In the final regression analysis model, which analyzed the impact of all four predictor variables on the criterion variable, English language performance of the EFL learners. The model 5 confirmed that mastery avoidance orientation was the most significant predictor with a higher beta weight compared to other variables $(\beta=.302 ; t=4.553 ; p<0.001)$. Next, it was performance avoidance orientation had lower beta weight $(\beta=-.215 ; t=-4.108 ; p<0.001)$. The third significant predictor in this model is mastery approach orientation $(\beta=.189 ; t=2.853$; $p<0.05)$. The last significant predictor is performance approach orientation $(\beta=.148 ; t=2.508$; $\mathrm{p}<0.05)$.

In conclusion, the step-wise multiple regression analysis was conducted and a regression model comprising four predictor variables and the dependent variable which is English language performance of EFL learners was conducted. The predictors are achievement goal orientations. In Table 2, it showed the results of step-wise multiple regression analysis. Out of four predictor variables entered in the model, four predictor variables which are mastery approach orientation, mastery avoidance orientation, performance approach orientation and performance avoidance orientation were considered as important predictor variables. In the model 5 , the value of $R^{2}$ was 0.256 and adjusted $R^{2}$ was 0.245 . The results revealed that $25.6 \%$ of variance in the dependant variable can be attributed to the four predictor variables.

\section{Discussion}

These overall positive perceptions displayed by the respondents are indicative of the fact that they are positive learners who are motivated to learn. Studies conducted by LinnenbrinkGarcia, Tyson and Patall (2008); Bong (2009) have revealed that a positive approach towards mastery goals are beneficial to academic achievement. This was also reiterated by Anderman \& Johnston (1998) who stressed that mastery goals are viewed as predictive of mediators, such as affect or certain kinds of behaviours that are in turn related to achievement. Therefore, these students with an overall positive and moderate level of mastery approach orientation towards learning are likely to engage in achievement-promoting behaviours and have the potential to focus on developing new skills, improving themselves and moving forward to acquiring additional knowledge and skills (Linnenbrink-Garcia, Tyson and Patall, 2008; Barron \& Harackiewicz, 2001; Daniels et al., 2009; Skaalvik, 1997; Anderman and Patrick, 2012). Mastery approach orientation is related to some positive effects, such as deep learning, high interest, high persistence and help seeking. However, although it has these beneficial effects, evidence shows that few students who use mastery goal orientation obtain high academic achievement (Rose \& Smith, 2014).

Furthermore, studies have also revealed that students who adopted performance approach goal orientations can gain higher academic achievement in their subject compared to their peers who adopted any other type of achievement goals (Alrakaf, et al. 2014). However, in another study research (Neuenhaus, et al., 2018), performance goal orientation was the 
negative predictor of achievement in the domain of reading and EFL and also affected later metacognitive knowledge in both domains in a negative way. In line with previous finding, performance goal orientation is the negative predictor of the two domains. Although students at the beginner level in EFL learning, have to deal with rather basic tasks, higher performance goal orientation tended to correspond with lower academic achievement.

\section{Conclusion}

The purpose of the study was to investigate the relationship between achievement goal orientations and growth mindset. The findings indicated that there was a significant and positive relationship between achievement goal orientations and language performance. Mastery approach orientation and mastery avoidance orientation showed a significant, moderate and positive relationship, performance approach orientation showed a significant, low and positive relationship and performance avoidance orientation showed a very low and negative relationship with language performance. Furthermore, the study also revealed that among all the predictors of language performance in English, mastery avoidance orientation was the most significant predictor with a higher beta weight compared to other variables. Next, it was performance avoidance orientation with a lower beta weight. The third significant predictor in this model is mastery approach orientation. The last significant predictor is performance approach orientation.

\section{Limitations and Future Studies}

At this juncture it is pertinent to note that the findings of this study cannot be generalized on the total population of EFL secondary school students in Hubei province or all the students from China due to a number of limitations. The first limitation lies in the sample size of this study. The sample of this study included only five (5) secondary schools and involved a total of 360 students. Therefore, future studies should involve more secondary schools from other provinces in China so that the results may lead to a more convincing conclusion.

Secondly, the scope of the study involved only factor, achievement goal orientations which was measured employing students' self-reporting behaviors via a questionnaire. This cannot guarantee that they offered true and honest opinions. Future studies may analyze personal prior experience, history of achievement, parents' goal orientation and value beliefs. Data can also be collected involving more research instruments such as interviews which will allow the researcher to triangulate data obtained from the questionnaire.

Despite the above limitations, there is no doubt that this study has shed some light on the status and relationship of achievement goal orientations on secondary school EFL students' language performance in Hubei, China.

\section{References}

Ames, C., \& Archer, J. (1988). Achievement goals in the classroom: Students' learning strategies and motivation processes. Journal of Educational Psychology, 80, 260-267.

Anderman, E. M., \& Wolters, C. (2006). Goals, values, and affect: Influences on student motivation. In P. Alexander \& P. Winne (Eds.), Handbook of educational psychology (2nd ed., pp. 369-389). Mahwah, NJ: Lawrence Erlbaum Associates.

Bong, M. (2009). Age-related differences in achievement goal orientation. Journal of Educational Psychology, 101 , 879-896.

Ciani, K. D., \& Sheldon, K. M. (2010). Evaluating the mastery-avoidance goal construct: A study of elite college baseball players. Psychology of Sport and Exercise, $11,127-132$. 
Conroy, D. E., Elliot, A. J., \& Hofer, S. M. (2003). A $2 \times 2$ achievement goals questionnaire for sport: Evidence for factorial invariance, temporal stability, and external validity. Journal of Sport and Exercise Physiology, 25 , 456-476.

Creswell, J. W. (2003). Research design: Qualitative, quantitative, and mixed methods approaches(2nd ed.). Thousand Oaks: Sage.

Elliot, A. J. (1999). Approach and avoidance motivation and achievement goals. Educational Psychologist, $34,169-189$.

Elliot, A. J., \& Harackiewicz, J. M. (1996). Approach and avoidance achievement goals and intrinsic motivation: A mediational analysis. Journal of Personality and Social Psychology, 70 , 461-475.

Elliot, A. J., \& McGregor, H. A. (2001). A $2 \times 2$ achievement goal framework. Journal of Personality and Social Psychology, $80,501-519$.

Elliot, A. J., McGregor, H. A., \& Gable, S. (1999). Achievement goals, study strategies, and exam performance: A mediational analysis. Journal of Educational Psychology, 91 , 549-563.

Harackiewicz, J. M., Barron, K. E., Carter, S. M., Lehto, A. T., \& Elliot, A. J. (1997). Predictors and consequences of achievement goals in the college classroom: Maintaining interest and making the grade. Journal of Personality and Social Psychology, 73 , 1284-1295.

Middleton, M. J., \& Midgley, C. (1997). Avoiding the demonstration of lack of ability: An underexplored aspect of goal theory. Journal of Educational Psychology, 89, 710-718.

Urdan, T., \& Mestas, M. (2006). The goals behind performance goals. Journal of Educational Psychology, 98 , 354-365.

Zhao, Y., \& Campbell, K. P. (1995). English in China. World Englishes, 14(3) 377- 390. 